\title{
Multi-objective scheduling in an agent based Holonic manufacturing system
}

\author{
T. K. Jana ${ }^{a^{*}}$, B. Bairagi ${ }^{\mathrm{b}}$, S. Paul ${ }^{\mathrm{c}}$, Sk. Sahnawaj ${ }^{\mathrm{d}}$, B. Sarkar ${ }^{\mathrm{e}}$, J. Saha ${ }^{\mathrm{f}}$
}

${ }^{a}$ Department of Mechanical Engineering, Haldia Institute of Technology, Haldia 721 657, India

${ }^{b}$ Department of Production Engineering, Haldia Institute of Technology, Haldia 721 657, India

${ }^{c}$ Department of Information Technology, Haldia Institute of Technology, Haldia, 721 657, India

${ }^{d}$ Department of Computer Application, Haldia Institute of Technology, Haldia, 721 657, India

${ }^{e}$ Department of Production Engineering, Jadavpur University, Kolkata 700 032, India

${ }^{f}$ Department of Production Engineering, Jadavpur University, Kolkata 700 032, India

\section{H R O N I C LE}

Article history:

Received May 12, 2013

Accepted June 22, 2013

Available online

July 162013

Keywords:

Multi-objective scheduling

Holonic manufacturing system

Multi agent system

Multi criteria decision making

Priority rule

Scheduling rule

\begin{abstract}
A B S T R A C T
The present paper is aimed at multi-objective scheduling in an agent based holonic manufacturing system to satisfy the goal of several communities namely the product, the resource, and the organization simultaneously. In this attempt, first a multi criteria based priority rule is developed following Simple Additive Weight (SAW) method under Multi Criteria Decision Making (MCDM) environment to rank the products. Accordingly, the products are allowed to select a particular resource for execution by negotiation considering minimum time as criterion. The interests of different communities are accomplished by allocating the ordered rank of products to the ordered rank of resources. Conflict, if arises between products and resources, are resolved by introducing the concept of Early Finish Time (EFT) as criterion for task allocation. A scheduling algorithm is proposed for execution of the rule. In view of machine failure, a cooperation strategy is evolved that also optimizes reallocation of the incomplete task. It is concluded that the proposed scheduling algorithm together with the disturbance handling algorithm are poised to satisfy the agent's local objective as well as organization's global objective concurrently and are commensurable with multi agent paradigm.
\end{abstract}

(C) 2014 Growing Science Ltd. All rights reserved.

\section{Introduction}

The foundation of Holonic manufacturing system (HMS) is built on the concept of negotiation and cooperation based work of different functional entities of the system, called holons. This is to confront growing complexities in business perspective such as highly stringent customer-specific product configurations with wide diversities, reduced time to market, unblemished product quality, world-wide competition, and reduced cost (Brussell et al., 1998, 1999). These holons are autonomous and self-reliant (Wang, 2001) by virtue of which, manifest agility and offer very high degrees of

* Corresponding author.

E-mail addresses: tarun.jana2000@gmail.com (T. K. Jana)

(C) 2013 Growing Science Ltd. All rights reserved. doi: $10.5267 /$ j.ds1.2013.07.003 
flexibility. A holon can have a physical part and an information processing part. Two other important attributes of holonic systems are recursivity and integrability (Gou et al., 1998). A system of holons that are engaged to achieve a common goal is called a holarchy. The control structure of holonic systems exhibit blending of hierarchy and heterarchy to derive their benefits and eliminate their shortcomings, simultaneously. Such systems provide adequate robustness against disturbances and remain unperturbed.

In multi agent system (MAS), a complex manufacturing system is divided into large numbers of small manageable agents that are autonomous, have intelligence to take their own decision, can perceive the environment and respond accordingly and can also communicate and cooperate with others (Christo \& Cardeira 2007). The holonic behavior is realized by MAS. An agent possess behavioral attributes like autonomy (ability to take one's own decision by virtue of pro-activeness), social ability (interacts with other agents by mutual message-based communication) and reactivity (agents can sense and respond to changes in the environment) (Wooldrigde \& Jennings, 1995; Christo $\&$ Cardeira, 2007). These systems rely on the principle of Distributed Problem Solving (DPS) (Davis \& Smith, 1983) where a set of modules co-operate dynamically amongst themselves to execute a task. Detailed study of HMS and MAS is credited to several authors Brussell et al. (1998, 1999); Giret and Botti (2004); Babiceanu and Chen, (2006); Shen et al. (2006a, 2006b); Leitao, (2009).

Traditionally, scheduling is an activity in the shop floor that considers time as a single parameter to optimize. This practice is however of little significance in an agent based system due to following reasons - (a) Agents are self-sustainable, smart, and intelligent; negotiate on different issues from their community perspective and finally settle the agreement, (b) Agents belonging to the same group are highly competitive and vie with each other to augment one's own credential, earnings etc., (c) Importance laid on different attributes are also varying, (d) The issues of different agent communities are often contradictory. For instance, a product may have very shorter due date (high urgency) and therefore interested in early processing. However, this product may not be attractive from the resource community due to low revenue generation, simple configuration, coarse tolerance etc. and hence may not be given high priority. Further, resources local goal may not be in good agreement with the global goal of the system. Scheduling in such environments therefore ought to consider varieties of techno-commercial issues (multiple objectives) of varying importance pertaining to different communities and becomes one of the critical issues to be addressed.

Scheduling in manufacturing industries is an activity of allocation/assignment of task(s) to the resources with respect to some time frame subject to a set of constraints and envisaged as NP-hard type problem (Shen et al., 2006a). The job-shop scheduling problem (JSSP) can be described as a set of $n$ products, denoted by $P_{j}$ where $j=1, . . n$ which have to be processed on a set of $m$ resources

denoted by $R_{i}$ where $i=1, . . m$. Unfortunately, most of the real-life situations being highly volatile and confronted with frequent occurrences of disturbances; the schedule made before hand hardly find any relevance in the shop floor and hence require dynamic modifications of it. Techniques like Lagrangian relaxation (Gou et al., 1998), constraints satisfaction (Miyashita, 1998), heuristics (Kutanoglu \& Sabuncuoglu, 1999), reinforcement learning (Wang \&Usher, 2005), neural networks and inductive learning (Priore et al., 2006; Iwamura et al., 2006), genetic algorithm (Alvarez and Diaz, 2007) are found to deal with dynamic scheduling problem. However, these techniques are fundamentally being centralized in nature and based on simple theoretical model; not commensurable with complex practical situations (Shen et al., 2006a).

The multi-agent systems (MAS) paradigm provides a very potential approach to dynamic scheduling problem and has gained considerable attention. It has several distinguished advantages (Shen, 2002; Cao et al., 2009). A great deal of elaboration regarding applications of agent based systems in 
manufacturing and scheduling is reported in literatures (Rabelo et al., 1999; Heragu et al., 2002; Shen et al., 2006a; 2006b).

In comparison to the traditional system, scheduling in MAS environment ought to address several issues from different participating communities simultaneously. Markus et al. (1996) proposed solutions to resolve conflicting issues like profit of the individual versus profit of the organization and meeting the deadline simultaneously by task scheduling, generated via a market mechanism that converts the scheduling problem into an economical problem. The conflict arises from concurrent persuasion of global goal and individual goal is avoided by enforcing the agents to obey rules derived from market mechanism. Duffle and Prabhu (1994) developed an architecture for real-time distributed scheduling based on heterarchical manufacturing systems to accomplish local goal and global goal together. The scheduler in each virtual entity generates a new local plan using local heuristics based on local information using Look-Ahead cooperative algorithm and the same is evaluated in the light of global merit (part production deadline), and eventually a particular local plan having the best global merit is established. Yang and Lin (1998) proposed a hybrid hierarchical/heterarchical shop floor control system in job dispatching using multiple criteria - the production price and the utilization rate of each cell. A task is awarded to a cell that can execute it at minimum cost, provided the loading rate of the cell is below a threshold value. Walker et al. (2005) used heuristics to solve dynamic scheduling problem in MAS based holonic manufacturing system. The authors attempted to combine heuristic job shop-scheduling approaches coupled with emerging AI techniques to create a dynamic and responsive scheduler to coordinate the local optimization of resource agent with the global optimization of the work cell and the shop floor. Li et al. (2008) combined genetic algorithms and heuristic rules for job-shop dynamic scheduling based on multi agent system. The tasks are allocated initially following Contract Net Protocol (CNP) (Smith, 1980) and rescheduling is done by hybrid-genetic algorithm to achieve global optimization. Wong et al. (2006) developed an agent-based approach for the dynamic integration of the process planning and scheduling. Two algorithms are developed to monitor the agent's individual decision are compatible with the global objectives. Wang et al. (2008) developed dynamic distributed scheduling algorithms in a multi-agent system based distributed shop floor control structure. At the work cell level, the scheduler allocates jobs to resources and deals with any dynamic events locally otherwise, it collaborates with the other peer schedulers of work cells.

The objective of the present work is to execute multi objective scheduling in an agent based holonic manufacturing system to satisfy the intended need of the several community. In this attempt, products priority is first developed by SAW technique under MCDM paradigm considering five different criteria that are appropriate to capture the issues for products, resource, and the organization. Finally, a schedule rule is proposed for task allocation. Furthermore, a disturbance handling mechanism is also presented to deal with the resource malfunctioning.

\section{The proposed Holonic manufacturing system and scheduling objectives}

In the present work, a holonic manufacturing system is developed comprising product holon, resource holon and integrated process planning and scheduling holon as shown in Fig. 1.

The activities of the Product holon includes getting the list of operations and rank (priority) from the integrated process planning and scheduling holon for negotiation with the resources, finalize the agreement, and monitor the progress of conversion. It also interacts with other resources in view of malfunctioning of the stipulated resource so as to get the work completed at the earliest, if possible. Eight different products $\left(\mathrm{P}_{1} \ldots \mathrm{P}_{8}\right)$ are considered for manufacturing. 
Resource holon includes three Turning Centers $\left(\mathrm{R}_{1} \ldots \mathrm{R}_{3}\right)$ of different capacity and specifications. A resource holon controls a machine tool (physical part) and monitors the entire range of activities of the machine. The information processing part is responsible for accessing its technical abilities in response to a task and evaluates a product from its own perspective and passes on these information to the scheduling holon for product ranking. It obtains operation plan from process planning holon, based on which it computes machining time and incorporates it in the BID. The resources also seek modified/new operation plan based on modified tool path and/or facilities, if the situation demands. Further, resources may interact with each other to achieve cooperation based work.

Integrated Process planning \& Scheduling holon generates the required operation plan considering raw material quality and size of the blank, facilities and tooling available for a particular resource. Once the product is launched, this holon prepares the operation plan and issues the same to the product as well as to the resources for necessary negotiation based task allocation. The alternative operation plan is also developed in view of modifications in facilities (e. g. changes in the cutting tool calls for modifications of the operational parameters). The scheduling holon is responsible for developing priority of the products and framing the scheduling rule considering the objective of different community i.e. the product, the resource and the organization as a whole simultaneously. The products and resources abide by these rules during negotiation based task allocation.

Once negotiation between any product $\left(P_{j}\right)$ and any resource $\left(R_{i}\right)$ is finalized following a particular process plan, corresponding schedule $\left(S_{i-j}\right)$ is generated and accordingly a dynamic cluster is formed as shown in Fig. 1.

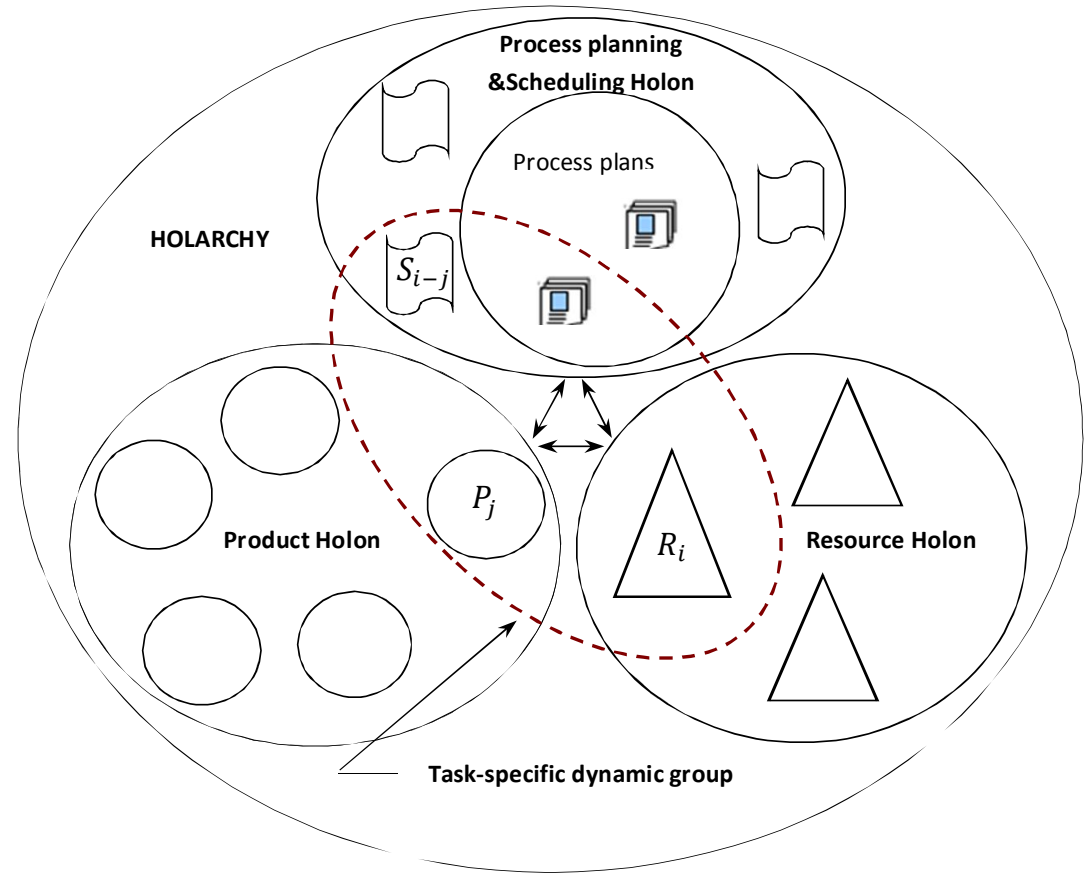

Fig. 1. Proposed Holonic manufacturing system

In the proposed system, objectives of three different communities are shown in Table 1 and these are required to be fulfilled in the scheduling. 
Table 1

Different communities and their objectives

Community Objectives

The Product Earliest possibility of processing

$\begin{array}{ll}\text { The Resource } & \text { Enhancing credentials, reputations, and earnings by processing challenging and lucrative products } \\ \text { The Organization } & \text { Address customer's need, high revenue generation, better resource utilization and load balancing }\end{array}$

\section{Achieving multi-objective scheduling}

The multi-objective scheduling is accomplished by following a two-tier procedure.

(i) Developing priority rule for products

(ii) Evolving scheduling rule for task allocation

\subsection{Priority rule for scheduling}

Priority or dispatching rules are rational approach followed to assign priority to jobs waiting for execution on a certain resource where assigned priorities are calculated according to the parameters related to jobs like arrival time, duration of the operation (SPT or WSPT), or due date (EDD) etc. (Badr, 2008). Sousa and Ramos (1999) used priority rule to avoid conflict for negotiation based task scheduling in a holonic control framework, where the task's priority is a function of the customer, the order value and the due date. Glanzer et al. (2001) used ZEUS agent to realize agent based scheduling, where priority of execution of a task is first governed by cost followed by duration. Leitao and Restivo (2002) considered priority of a new order in terms of early due date. Wong et al. (2006) introduced a fictitious cost element to determine scheduling priority of job. This cost is a function of critical ratio defined as ratio of due date and total processing time. Eguchi et al. (2008) developed a robust and effective scheduling rule using a neural network $(\mathrm{NN})$ which is considered as a priority rule for the complex and dynamic job-shops. Papakostas and Chryssolouris (2009) adopted a new scheduling policy called RTSLACK for improving tardiness and found to be superior as compared to EDD, SPT and SLACK. Sudo et al. (2010) developed an arrow diagram (PERT) to derive priority of a job in an assembly line. In their work, least node time (LNT) is considered to adjudged priority between two jobs (components) of a product. However, for jobs belonging to different products, additionally post assembly processes and deadline are also considered to assign priority.

Multi-criteria decision making (MCDM) techniques generically rank and select alternatives by their composite values or scores in a ratio scale (Shih, 2008). It is a systematic procedure of finding the best alternative or ranking the alternatives among a set of feasible alternatives having multiple conflicting criteria of varying importance. All criteria of a MCDM problem can be classified into two groups: beneficial (B) for which higher values are desirable and non beneficial (NB) for which lower values are desirable. The concept of combining the fuzzy theory and MCDM is referred to as FMCDM. A fuzzy MCDM model is used to assess alternatives versus selected criteria, where attribute values and the importance weights of criteria are expressed in linguistic values represented by fuzzy numbers (Bashiri et al., 2012). The units of performance rating as well as their range of magnitude being different are normalized to convert the criteria into dimensionless attributes in the range 0 to 1 . We adopt SAW method since it is simple, reliable as well as robust. Furthermore, its computation procedure does not involve complex mathematics (Janic and Reggiani, 2002) and therefore amenable for implementation in MAS environment.

\subsubsection{Saw method}

The stepwise procedures of SAW technique is presented below. 
Step 1: Formation of decision matrix with performance scores. Performance score or performance rating is the value of alternative on each criterion provided by the decision maker.

$$
\begin{aligned}
& \begin{array}{lllll}
C_{1} & \ldots & C_{j} & \ldots & C_{n}
\end{array} \\
& D=\begin{array}{c}
A_{1} \\
\ldots \\
A_{i} \\
\ldots \\
A_{m}
\end{array}\left[\begin{array}{ccccc}
x_{11} & \ldots & x_{1 j} & \ldots & x_{1 n} \\
\ldots & \ldots & \ldots & \ldots & \ldots \\
x_{i 1} & \ldots & x_{i j} & \ldots & x_{i n} \\
\ldots & \ldots & \ldots & \ldots & \ldots \\
x_{m 1} & \ldots & x_{m j} & \ldots & x_{m n}
\end{array}\right]
\end{aligned}
$$

where $x_{i j}$ is the performance rating of alternative $A_{i}$ with respect to criterion $C_{j} . m$ is the number of alternatives and $n$ is the number of criteria. Here the performance rating $x_{i j}$ is either crisp or fuzzy expressed as $x_{i j}=\left(a_{i j}, b_{i j}, c_{i j}\right)$.

Step 2: Formation of weight matrix.

$W=\left[\begin{array}{lllll}\tilde{w}_{1} & \ldots & \tilde{w}_{j} & \ldots & \tilde{w}_{n}\end{array}\right]$

where, $\widetilde{w}_{j}=\left(\alpha_{j}, \beta_{j}, \gamma_{j}\right)$ is weight of criterion $j$.

Step 3: Defuzzification of performance score by the equation

$$
\bar{x}_{i j}=\frac{1}{3}\left(a_{i j}+b_{i j}+c_{i j}\right)
$$

Step 4: Defuzzification of weight by the equation

$$
\bar{w}_{j}=\frac{1}{3}\left(\alpha_{j}+\beta_{j}+\gamma_{j}\right)
$$

Step 5: Construct final decision matrix

$D^{\prime}=\left[x_{i j}^{\prime}\right]_{m \times n}$

where, $x_{i j}^{\prime}=x_{i j}$ for objective criteria and $x_{i j}^{\prime}=\bar{x}_{i j}$ for subjective criteria.

Step 6: Normalization of score of alternative is obtained using following equations

For benefit criteria $j$

$$
x_{i j}^{N}=\frac{x_{i j}^{\prime}}{\max _{i}\left(x_{i j}^{\prime}\right)}
$$

For non-benefit criteria $j$

$$
x_{i j}^{N}=\frac{\min _{i}\left(x_{i j}^{\prime}\right)}{x_{i j}^{\prime}}
$$

Step 7: Normalization of importance weights of criteria is carried out using following equation

$$
w_{j}^{N}=\frac{\bar{w}_{j}}{\sum_{j=1}^{n} \bar{w}_{j}} \text { where } \sum_{j=1}^{n} w_{j}^{N}=1
$$

Step 8: Computation of Composite Score $\left(C S_{i}\right)$ for alternative $i$

$$
C S_{i}=\sum_{j=1}^{n}\left(w_{j}^{N} * x_{i j}^{N}\right)
$$


Step 9: Ranking the products in descending order of composite scores $\left(C S_{i}\right)$. Higher $C S_{i}$ of alternative is better and desirable and alternative having highest $C S_{i}$ is selected as the best one that corresponds to the best performance.

\subsection{Scheduling Rule}

Once the priorities of the products are established, they negotiate with the resources following wellknown Contract Net Protocol (CNP) (Smith, 1980) and finalize the agreement and thus local schedule is prepared. The products select the resources using the minimum processing time as the criterion. The scheduler evolves a schedule rule which ensures that objectives of different communities i.e. the product, the resource, and the organization are satisfied simultaneously.

The following assumptions are made for execution of the schedule rule:

- There is no pre-emption, no set up time.

- A particular resource can deal with only one product at a time.

- Each product is processed till its completion without any break unless there is any resource malfunctioning.

- No resource would remain idle, unless it is redundant

The following schedule rule is proposed to optimize the task allocation to resources

- The ordered rank of products would be assigned to the ordered rank of resources

- Exception, if any, is resolved by trade-off practice with more emphasis on the customer requirements $i$. e. the products. Under such condition, the products would be allocated to the resources using the criterion of Early Finish Time (EFT).

Three different situations can arise depending on the number of resources $(m)$ and the number of products $(n)$.

\section{$3.2 .1 n \leq m$}

When $n=m$, the rule yields that each resource deals with exactly one product. This ensures no resource remains idle. We adopt the policy that the products would be allowed to negotiate with the resources sequentially according to their rank as evaluated by the priority rule. Resources are ranked according to the criterion of minimum operation time. Thus the product having rank 1 would be allocated to the resource having corresponding rank i. e. 1. For the remaining products and resources, same rule is followed. When $n<m$, the task allocation procedure is same with only difference that ( $m-n$ ) number of resources would be surplus and hence become idle. However, such a situation seldom occurs in reality since resources are rarely made abundant.

\subsection{2 $n>m$}

When such a situation arises (this is the most common in reality), $m$ number of ordered rank of products are allocated to $m$ number of ordered rank of resources in the first phase, leaving $(n-m)$ number of products to wait in the queue. The possibility of allocation of such products arises when at least any one of the resources becomes free. At this juncture, indecision problem arises from the fact that the resource which has just becomes free may not be the best one. Two different communities the product and the resource have contradictory objectives; (i) the best resource always looks for lucrative products whereas; the products want to be processed at the earliest. To resolve this conflict, the scheduler adopts the policy that preference would be given to the customer requirements, $i$. e. to the products. In congruence with this philosophy, scheduler computes the EFT of the next product by resources and the product would be offered to one having minimum EFT. EFT of any product by any resource is computed as the time span from the origin or zero reference to the instance when the 
product can be completed. It is noteworthy that for comparison of EFT, only the current resource that has just becomes free and other superior resources are considered. An algorithm is developed and presented to execute the proposed schedule rule under all the aforesaid situations.

Following symbols are used in the algorithm

$R_{(i)}$ is the ordered rank of resources where $i=1, . . m$

$P_{(j)}$ is the ordered rank of products where $j=1, . . n$

$P_{(k)}$ is the product having $k$ th rank waiting in the queue for allocation to resources

$R_{i}^{\prime}$ is any arbitrary resource to which $P_{(k)}$ is finally allocated

\section{Algorithm}

1. Assign rank to products and resources

2. Allocate ordered rank of product $P_{(j)}$ to ordered rank of resource $R_{(i)}$

3. If $(n \leq m)$ then Goto Step 6

4. Else

5. For $(k=m+1$ to $n)$, repeat Step 5(a) to Step 5(c)

(a) Identify the rank of resource $R_{(i)}$ that has just become free

(b) Compute EFT for $(i)-1$ number of superior resources and for $R_{(i)}$ considering $P_{(k)}$ and find the resource $R_{i}^{\prime}$ having minimum EFT.

(c) Allocate $P_{(k)}$ to $R_{i}^{\prime}$

[end of step 5 loop]

6. Stop

Based on the outcome of the algorithm, products are allocated to the resources one by one to complete the schedule.

\subsection{Cooperation strategy for handling resource failure}

When any resource confronts a malfunctioning and can't recover immediately, it seeks help from others. Under this situation, the system migrates from hierarchical control and reconfigures into heterarchical control. The other active resources by virtue of cooperation try to accommodate the partially processed job of the faulty resource so as to get rid of the crisis. When a particular resource breaks down, either of the following two situations prevails regarding the status of the other working resources at that instant.

(i) A resource may be engaged with its own work, or (ii) It is just free after completion of a product and about to negotiate with the next one waiting in the queue.

We adopt the policy that the incomplete job would be allocated at the earliest possible opportunity and accordingly following course of action is proposed. If a resource is already engaged, then it continues with the work uninterruptedly to complete it and then attempts to accommodate the incomplete work of faulty resource. However, if a resource is just free, then it immediately tries to undertake processing of the incomplete work of faulty resource. When there are several active resources, the final candidate resource is determined by using the concept of EFT once again to ensure that re-allocation is optimized even under changing circumstances. In this attempt, each of the capable resources determines expected early finishing time $\left[E F T_{\text {exp }}\right]$ of the incomplete product. 
Finally, $\left[E F T_{\text {exp }}\right]$ so computed by each resource is sent to the faulty resource for comparison and the work is offered to one having the least EFT. $\left[E F T_{\exp }\right]_{R_{i}}^{P_{l} / R_{k}}$ of the incomplete product $P_{l}$ (partially processed by faulty resource $R_{k}$ before failure) by a capable resource $R_{i}$ is defined as the time span to finish this incomplete work from the instance of occurrence of breakdown of $R_{k}$. A sequential procedure is followed to adopt cooperation based work.

Following symbols are used in the procedural steps

$t_{b}$ is the time of breakdown of $R_{k}$

$t_{s}$ is the start time of $P_{l}$ by $R_{k}$

$\phi$ is the fractional progress of the product $P_{l}$ by $R_{k}$ at the time of break down.

$\left[\tau_{o p}\right]_{R_{k}}^{P_{l}}$ is the stipulated processing time of $P_{l}$ by $R_{k}$

$\left[\tau_{\text {reqd }}\right]_{R_{i}}^{P_{l} / R_{k}}$ is the time required to complete the balance work of $P_{l}$ by $R_{i}$ where $i=1,2, . ., m, i \neq k$

$\left[\tau_{o p}\right]_{R_{i}}^{P_{l}}$ is the stipulated processing time of $P_{l}$ by $R_{i}$

$\left[\tau_{\text {due }}\right]_{R_{i}}^{P_{j}}$ is the time due to complete $P_{j}$ by $R_{i}$ from the instance of occurrence of breakdown of $R_{k}$ where $j=1,2, . ., n, j \neq l$

Step 1: The faulty resource $R_{k}$ computes $\phi$ by the following relationship

$$
\phi=\frac{t_{b}-t_{s}}{\left[\tau_{o p}\right]_{R_{k}}^{P_{l}}}
$$

Step 2: $R_{k}$ then computes the fractional work left for $P_{l}$ using the following relationship

Work left $=1-\phi$

Step 3: Other resources compute the time required to complete the balance work of $P_{l}$ by the following relationship

$$
\left[\tau_{\text {reqd }}\right]_{R_{i}}^{P_{l} / R_{k}}=(1-\phi) \cdot\left[\tau_{o p}\right]_{R_{i}}^{P_{l}}
$$

Step 4: $\left[E F T_{\text {exp }}\right]_{R_{i}}^{P_{l} / R_{k}}$ is computed by each working resource which is expressed as follows

If a resource is already engaged,

$$
\left[E F T_{\text {exp }}\right]_{R_{i}}^{P_{l}^{\prime / R}}=\left[\tau_{\text {due }}\right]_{R_{i}}^{P_{j}}+\left[\tau_{\text {reqd }}\right]_{R_{i}}^{P_{l} / R_{k}}
$$

else

$$
\left[E F T_{\exp }\right]_{R_{i}}^{P_{l} / R_{k}}=\left[\tau_{\text {reqd }}\right]_{R_{i}}^{P_{l} / R_{k}}
$$

[end of if]

Step 5: $\left[E F T_{\text {exp }}\right]_{R_{i}}^{P_{l} / R_{k}}$ so computed is sent to the faulty resource. The faulty resource $R_{k}$ compares $\left[E F T_{\text {exp }}\right]_{R_{i}}^{P_{l} / R_{k}}$ of various resources and selects the least one for offering the task. 
Step 6: Exit.

\section{Schedule Execution}

\subsection{Product Prioritization}

The product holon comprises eight products $\left(\mathrm{P}_{1}\right.$ to $\left.\mathrm{P}_{8}\right)$ for machining by three resources $\left(\mathrm{R}_{1}\right.$ to $\left.\mathrm{R}_{3}\right)$. Scheduling attributes refer to the various criteria that play significant role to judge the merit of the products for establishing priority. These criteria are broadly classified into two groups: (a) technical criteria and (b) commercial criteria. Technical criteria are relevant to assess a product from a resource's own perspective so as to satisfy its individual objective. These criteria are obtained from part drawing and specifications of the material. Commercial criteria on the other hand are significant from business perspective. It is worth mentioning that benefits accrued by the organization when its business goals are satisfied, have positive consequences on the resources also. Thus it is possible to combine the resources local criteria and organizations global criteria so as to be satisfied simultaneously.

\subsubsection{Assessment of Criteria}

Revenue (C1): Revenue is considered as the most attractive criteria for the organization. Any successful completion of job is always accompanied by revenue generation and in the holonic environment each resource is supposed to get some fraction of this revenue. Thus high valued products are preferred by resources as well as by the organization.

Revenue generated from a product is computed by the following relationship and expressed in Indian Rupee (IR). Revenue $=$ Material cost + Conversion cost + Profit, where profit is considered as $20 \%$ of the total cost. It is expressed in Indian Rupee.

Machinability rating (C2): This is one of the most generic machining attributes that comprehensively captures numbers of technical aspects like reduced cutting force and power, enhanced tool life etc. which are considered favorable for machining and hence envisaged as benefit criteria. It is dimensionless and its values are obtained from Machinability data book.

Intricacy or complexity (C3): As opposed to general notion, this is considered as benefit criteria in the sense that a resource being intelligent, a capable resource always tries to deal with complex and challenging jobs to augment its credibility and reputation. Intricacy being a vague term is expressed by fuzzy numbers. The intricacy is judged by investigating the component drawing.

Precision (C4): Precision refers to the very stringent dimensional tolerance of the product which is required to be maintained during machining. Lower numeric value of precision is although difficult to maintain, but it is desirable by competent resources to undertake challenging jobs and considered as non benefit criteria. Its values are obtained from component drawings and expressed in $\mathrm{mm}$.

Due date (C5): Due date of a product is the time within which a product has to be completed. Lower due date of a product means high urgency and the organization would be ready to welcome the job of shorter due date so as to be remain competitive. A product having lower due date therefore should be given preference for early processing. In the present system, it is proposed that the products belongs to a single customer order and these are created at a particular time with an expectation that all would be completed within a particular time frame, without having any specific and individual due date. We, therefore, express due date by fuzzy numbers to establish the relative importance in regard to time frame of execution.

The vague attributes ( $\mathrm{C} 3$ and $\mathrm{C} 5)$ are converted into corresponding triangular fuzzy number (TFN) as per Table 2. The weights of the criteria are assigned according to the relative merits of the attributes and expressed by linguistic variables which are finally converted to TFN as per Table 3 . The initial 
decision matrix is formulated and shown in Table 4. The defuzzified decision matrix along with weight matrix is presented in Table 5. The SAW algorithm is implemented in MATLAB 7.5. Final normalized decision matrix, composite scores and rank of the products are presented in Table 6.

Table 2

Degree of performance rating

\begin{tabular}{ccc}
\hline Linguistic Variable & Abbreviation & TFN \\
\hline Very Poor & VP & $(0,1,3)$ \\
Poor & P & $(1,3,5)$ \\
Medium & M & $(3,5,7)$ \\
Good & G & $(5,7,9)$ \\
Very Good & VG & $(7,9,10)$ \\
\hline
\end{tabular}

Table 4

Initial decision matrix

\begin{tabular}{cccccc}
\hline Criteria & $\mathrm{C} 1(+)$ & $\mathrm{C} 2(+)$ & $\mathrm{C} 3(+)$ & $\mathrm{C} 4(-)$ & $\mathrm{C} 5(-)$ \\
\hline Weight & $\mathbf{H}$ & $\mathbf{M}$ & $\mathbf{M}$ & $\mathbf{M}$ & $\mathbf{V H}$ \\
\hline $\mathrm{P}_{1}$ & 3675 & 110 & $\mathrm{G}$ & 0.04 & $\mathrm{P}$ \\
$\mathrm{P}_{2}$ & 4980 & 30 & $\mathrm{VG}$ & 0.02 & $\mathrm{M}$ \\
$\mathrm{P}_{3}$ & 1795 & 55 & $\mathrm{M}$ & 0.06 & $\mathrm{M}$ \\
$\mathrm{P}_{4}$ & 3480 & 200 & $\mathrm{M}$ & 0.20 & $\mathrm{VP}$ \\
$\mathrm{P}_{5}$ & 1357 & 110 & $\mathrm{P}$ & 0.15 & $\mathrm{G}$ \\
$\mathrm{P}_{6}$ & 2596 & 300 & $\mathrm{G}$ & 0.04 & $\mathrm{G}$ \\
$\mathrm{P}_{7}$ & 2750 & 200 & $\mathrm{M}$ & 0.02 & $\mathrm{P}$ \\
$\mathrm{P}_{8}$ & 1320 & 85 & $\mathrm{P}$ & 0.10 & $\mathrm{M}$ \\
\hline NB: (+) implies benefit criteria and (-) implies non-benefit criteria & &
\end{tabular}

Table 3

Degree of weights of criteria

\begin{tabular}{ccc}
\hline Linguistic Variable & Abbreviation & TFN \\
\hline Very Low & VL & $(0,0.1,0.3)$ \\
Low & L & $(0.1,0.3,0.5)$ \\
Moderate & M & $(0.3,0.5,0.7)$ \\
High & H & $(0.5,0.7,0.9)$ \\
Very High & VH & $(0.7,0.9,1.0)$ \\
\hline
\end{tabular}

Table 5

Defuzzified decision matrix along with weight matrix

\begin{tabular}{cccccc}
\hline Criteria & $\mathrm{C} 1(+)$ & $\mathrm{C} 2(+)$ & $\mathrm{C} 3(+)$ & $\mathrm{C} 4(-)$ & $\mathrm{C} 5(-)$ \\
\hline Weight & $\mathbf{0 . 7}$ & $\mathbf{0 . 5}$ & $\mathbf{0 . 5}$ & $\mathbf{0 . 5}$ & $\mathbf{0 . 8 6 7}$ \\
\hline $\mathrm{P}_{1}$ & 3675 & 110 & 7 & 0.04 & 3 \\
$\mathrm{P}_{2}$ & 4980 & 30 & 8.67 & 0.02 & 5 \\
$\mathrm{P}_{3}$ & 1795 & 55 & 5 & 0.06 & 5 \\
$\mathrm{P}_{4}$ & 3480 & 200 & 5 & 0.20 & 1.33 \\
$\mathrm{P}_{5}$ & 1357 & 110 & 3 & 0.15 & 7 \\
$\mathrm{P}_{6}$ & 2596 & 300 & 7 & 0.04 & 7 \\
$\mathrm{P}_{7}$ & 2750 & 200 & 5 & 0.02 & 3 \\
$\mathrm{P}_{8}$ & 1320 & 85 & 3 & 0.10 & 5 \\
\hline
\end{tabular}

Table 6

Normalized decision matrix, composite score, and rank

\begin{tabular}{cccccccc}
\hline Criteria & $\mathrm{C} 1(+)$ & $\mathrm{C} 2(+)$ & $\mathrm{C} 3(+)$ & $\mathrm{C} 4(-)$ & C5 (-) & CS & Rank \\
\hline Weight & $\mathbf{0 . 2 2 8 2}$ & $\mathbf{0 . 1 6 3 0}$ & $\mathbf{0 . 1 6 3 0}$ & $\mathbf{0 . 1 6 3 0}$ & $\mathbf{0 . 2 8 2 7}$ & & \\
\hline $\mathrm{P}_{1}$ & 0.7380 & 0.3667 & 0.8074 & 0.5000 & 0.4433 & 0.5667 & \\
$\mathrm{P}_{2}$ & 1.0000 & 0.1000 & 1.0000 & 1.0000 & 0.2660 & 0.6458 & 2 \\
$\mathrm{P}_{3}$ & 0.3604 & 0.1833 & 0.5767 & 0.3333 & 0.2660 & 0.3357 & 6 \\
$\mathrm{P}_{4}$ & 0.6988 & 0.6667 & 0.5767 & 0.1000 & 1.0000 & 0.6612 & 1 \\
$\mathrm{P}_{5}$ & 0.2725 & 0.3667 & 0.3460 & 0.1333 & 0.1900 & 0.2538 & 8 \\
$\mathrm{P}_{6}$ & 0.5213 & 1.0000 & 0.8074 & 0.5000 & 0.1900 & 0.5488 & 5 \\
$\mathrm{P}_{7}$ & 0.5522 & 0.6667 & 0.5767 & 1.0000 & 0.4433 & 0.6171 & 3 \\
$\mathrm{P}_{8}$ & 0.2651 & 0.2833 & 0.3460 & 0.2000 & 0.2660 & 0.2709 & 7 \\
\hline
\end{tabular}

\subsection{Scheduling}

The proposed scheduling algorithm is implemented using HTML code in front-end with Java Server Page (JSP) through Apache Tomcat 6.02 server. The machining time for different product-resource combinations are shown in Table 7

Table 7

Machining time (minutes) of various product- resource combinations

\begin{tabular}{cccc}
\hline \multirow{2}{*}{ Product } & & Resource & \\
\cline { 2 - 4 } & $\mathrm{R}_{1}$ & $\mathrm{R}_{2}$ & $\mathrm{R}_{3}$ \\
\hline $\mathrm{P}_{1}$ & 25 & 31 & 37 \\
$\mathrm{P}_{2}$ & 18 & 23 & 28 \\
$\mathrm{P}_{3}$ & 12 & 13 & 16 \\
$\mathrm{P}_{4}$ & 19 & 21 & 24 \\
$\mathrm{P}_{5}$ & 5 & 7 & 8 \\
$\mathrm{P}_{6}$ & 10 & 12 & 14 \\
$\mathrm{P}_{7}$ & 8 & 11 & 13 \\
$\mathrm{P}_{8}$ & 12 & 15 & 17 \\
\hline
\end{tabular}


Since the numbers of products are more than the numbers of resources, all the products can't be allocated to the resources in the $1^{\text {st }}$ phase. According to the scheduling strategy, the products $\mathrm{P}_{4}, \mathrm{P}_{2}$ and $\mathrm{P}_{7}$ are allocated to $\mathrm{R}_{1}, \mathrm{R}_{2}$ and $\mathrm{R}_{3}$ respectively. For the remaining products the EFT rule is followed. The scheduling holon thus prepares the global schedule for different resource-product combinations. The complete schedule is shown by Gantt chart in Fig. 2.

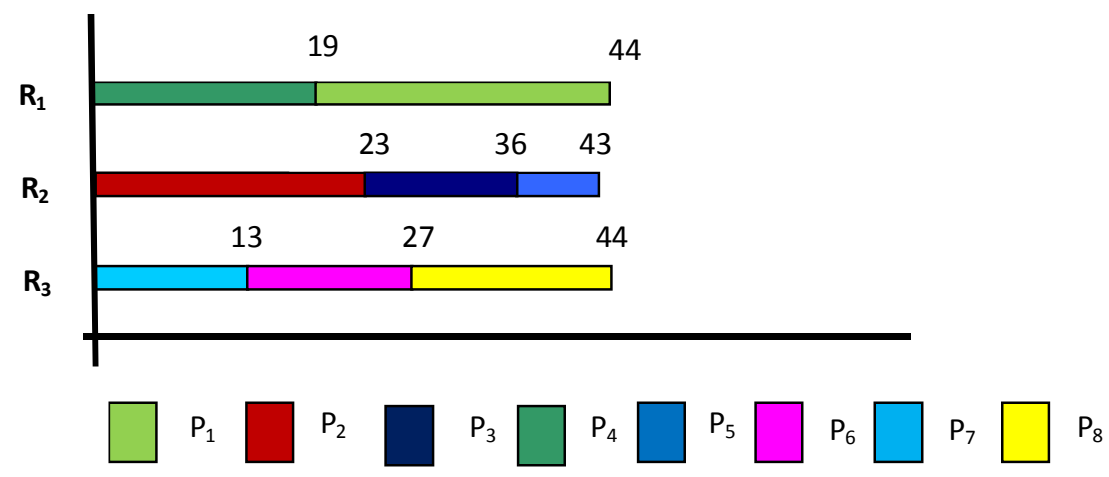

Fig. 2. Gantt chart showing schedule under normal condition

\subsection{Cooperation based scheduling under disturbances}

When a resource confronts any malfunctioning, cooperation based work helps to overcome the situation. To validate the proposed cooperation mechanism, three different bottleneck scenarios are considered. The break down details and the procedural outcome is presented in Table 8. After the incomplete work is re-allocated, the original schedule rule is enforced once again for the remaining products. The corresponding schedules are shown in Fig. 3 by Gantt charts.

Table 8

Details of resource break down

\begin{tabular}{cccccc}
\hline Scenario & $\begin{array}{c}\text { Break down } \\
\text { resource }\end{array}$ & $\begin{array}{c}t_{b} \\
\text { (minutes) }\end{array}$ & $P_{l}$ & {$\left[E F T_{\text {exp }}\right]_{R_{i}}^{P^{\prime} R_{k}}$ (minutes) } & $\begin{array}{c}\text { Final } \\
\text { candidate resource }\end{array}$ \\
\hline $\mathrm{D} 1$ & $\mathrm{R}_{1}$ & 15 & $\mathrm{P}_{4}$ & $\mathrm{R}_{2}=12.41 \mathrm{R}_{3}=17.04$ & $\mathrm{R}_{2}$ \\
$\mathrm{D} 2$ & $\mathrm{R}_{2}$ & 13 & $\mathrm{P}_{2}$ & $\mathrm{R}_{1}=13.74 \quad \mathrm{R}_{3}=12.04$ & $\mathrm{R}_{3}$ \\
$\mathrm{D} 3$ & $\mathrm{R}_{3}$ & 32 & $\mathrm{P}_{8}$ & $\mathrm{R}_{1}=20.52 \quad \mathrm{R}_{2}=14.65$ & $\mathrm{R}_{2}$ \\
\hline
\end{tabular}

\section{Results and Discussion}

The proposed multi-objective scheduling is carried out for eight products considering three resources in an agent based holonic system by adopting a two-stage procedure. The product ranking by SAW technique shows the order as $\mathrm{P}_{4}>\mathrm{P}_{2}>\mathrm{P}_{7}>\mathrm{P}_{1}>\mathrm{P}_{6}>\mathrm{P}_{3}>\mathrm{P}_{8}>\mathrm{P}_{5}$. The resources are ranked by minimum processing time that yields $\mathrm{R}_{1}>\mathrm{R}_{2}>\mathrm{R}_{3}$. According to the proposed schedule rule; $\mathrm{P}_{4}, \mathrm{P}_{2}$ and $\mathrm{P}_{7}$ are allocated to $R_{1}, R_{2}$ and $R_{3}$ respectively in the $1^{\text {st }}$ phase. For the remaining products, conflict is avoided by a compromise solution and the schedule is accomplished by the EFT rule. Unlike the work of Yang \& Lin (1998), the proposed scheduling procedure automatically ensures load balancing among the resources as the loading process continues without requiring any additional procedure. Furthermore, when any resource is confronted with malfunctioning and can't recover immediately, re-allocation procedure of incomplete work is also optimized. Since task re-allocation procedure is merged with the original schedule rule, the load balancing among the remaining working resources is still possible under disturbance as evident from Figure 3. However, since the number of working resource is reduced, the total make span is increased as seen in Figure 3. The Work-in-Progress (WIP) and the Mean Flow Time (MFT) under normal (N) as well as under disturbances (D1, D2 and D3) are presented in Table 9. 
Table 9

Scheduling performances

\begin{tabular}{ccc}
\hline Scenario & WIP & MFT \\
\hline N & 5.7 & 31.13 \\
D1 & 6.78 & 39.65 \\
D2 & 7.25 & 39.02 \\
D3 & 5.96 & 32.70 \\
\hline
\end{tabular}

Both WIP and MFT increase under disturbances in comparison to the normal situation. The changes are more pronounced in D1 and D2, since the failures take place at the early stages of execution. However, in case of D3, the consequences of break down are trivial since the failure occurs when substantial progress is already made.

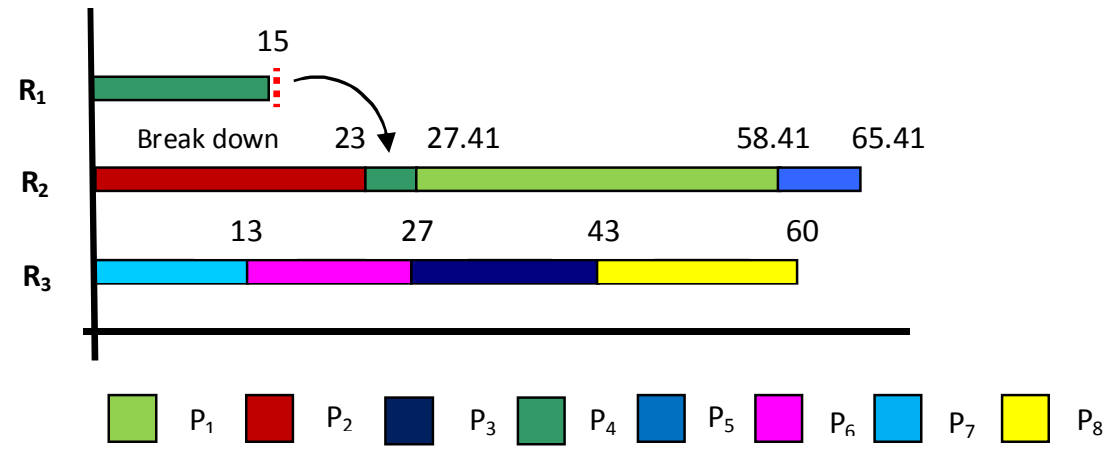

Schedule under D1

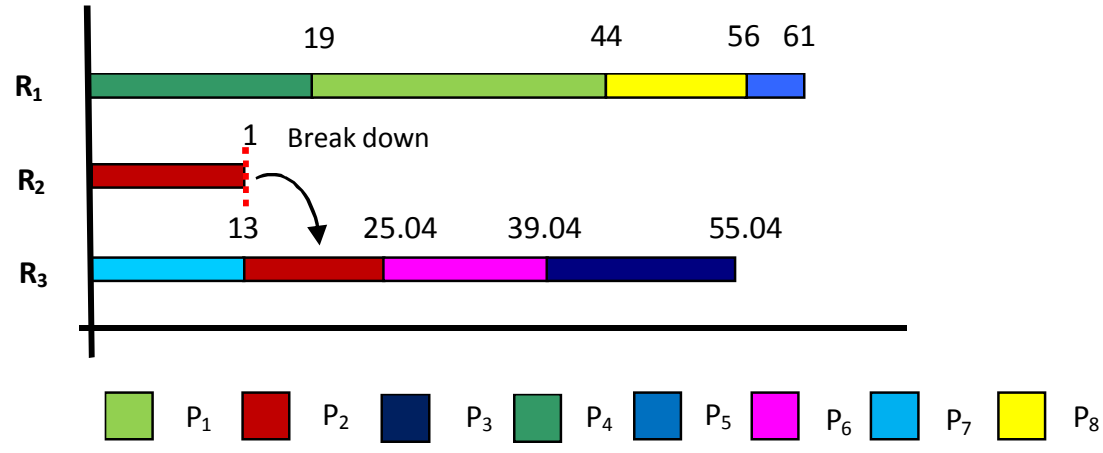

Schedule under D2

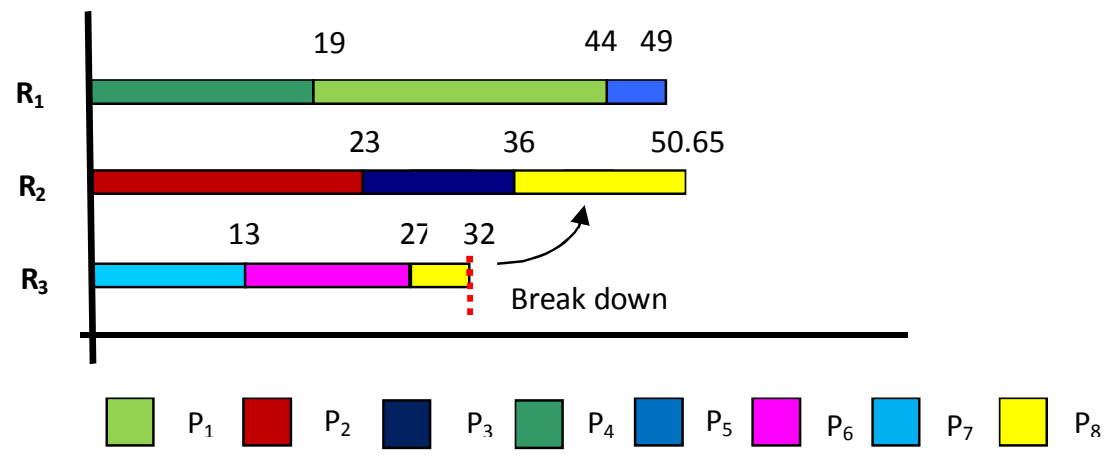

Schedule under D3

Fig. 3. Gantt charts showing schedules under the scenarios D1, D2, and D3 


\section{Conclusion}

The present paper deals with multi objective scheduling in an agent based holonic manufacturing system. The agents are being intelligent and self-sustained entities; the priority rule is developed from multiple attributes of different communities. Furthermore, the importance weights of the criteria have been assigned in a manner commensurable to the business environment. The SAW technique adopted is simple, yet accurate and offers robustness and therefore compatible in MAS environment. In view of new product addition, the technique can dynamically update the rank list without requiring any additional procedure. The scheduling strategy together with priority rule can simultaneously satisfy the need of the products, the resources and the organization as a whole in a most optimized manner. The strategy ensures that the competent and superior resources get the opportunity to process products which are compatible to their worth. The products in turn get the opportunity to be processed at the earliest according to their merit. Furthermore, whenever conflict arises, it is resolved by a trade-off practice that endows more importance to the products (hence the customer). The scheduling algorithm is simple, yet comprehensive to satisfy the need of all concern. Additionally, when break down takes place, the cooperation strategy also yields the best possible solution under changing circumstances. The proposed system follows a combination of hierarchical and heterarchical control in line with the basic holonic philosophy. The JSP programming facilitates to visualize product allocation to resources which helps in schedule (Gantt chart) preparation. Future work in this direction would investigate the solution to the challenges in more complex real-life situation.

\section{References}

Alvarez, E \& Diaz, F. (2007). Framework for the dynamic scheduling of complex job shops. International Journal of Manufacturing Technology and Management, 11 (3/4), 411-425.

Babiceanu, R.F \& Chen, F.F. (2006). Development and applications of holonic manufacturing systems: a survey. Journal of Intelligent Manufacturing, 17, 111-131.

Badr, I. (2008). An agent-based scheduling framework for flexible manufacturing systems. World Academy of Science, Engineering and Technology, 40, 363-369.

Bashiri, M., Koosha, M., \& Karimi, H. (2012). Permutation based decision making under fuzzy environment using Tabu search. International Journal of Industrial Engineering Computations, 3, 301-312.

Brussel, H.V., Wyns, J., Valckenaers, P., Bongaerts, L. \& Peeters, P. (1998). Reference architecture for holonic manufacturing systems: PROSA. Computers in Industry, 37 (3), 255-276.

Brussel, H.V., Bongaerts, L., Wyns, J., Valckenaers, P. \& Ginderachter, T.V. (1999). A conceptual framework for holonic manufacturing: Identification of manufacturing holons. Journal of Manufacturing Systems, 18 (1), 35-52.

Cao, Y., Yang, Y., Wang, H., \& L. Yang, L. (2009). Intelligent job shop scheduling based on MAS and integrated routing wasp algorithm and scheduling wasp algorithm. Journal of Software, 4 (5), 487-494.

Christo, C. \& Cardeira, C. (2007). Trends in intelligent manufacturing systems. International Symposium on Industrial Electronics, IEEE, Vigo, Spain, 3209- 3214.

Davis, R. \& Smith, R. (1983). Negotiation as a metaphor for distributed problem solving. Artificial Intelligence, 20 (1), 63-109.

Duffle, N.A, \& Prabhu, V.V. (1994). Real-time distributed scheduling of heterarchical manufacturing systems. Journal of Manufacturing Systems, 13 (2), 94-107.

Eguchi, T., Oba, F. \&Toyooka, S. (2008). A robust scheduling rule using a neural network in dynamically changing job-shop environments. International Journal of Manufacturing Technology and Management, 14 (3-4), 266 - 288.

Giret, A and Botti, V. (2004). Holons and agents. Journal of Intelligent Manufacturing, 15, 645-659. 
Glanzer, K., Hammerle, A. \& Ralf Geurts, R. (2001). The Application of ZEUS agents in manufacturing environments. Proceedings of the $12^{\text {th }}$ International Workshop of IEEE on Database and Expert Systems Applications, IEEE Computer Society, Munich, Germany, 628-632.

Gou, L., Luh, P.B. \& Kyoya, Y. (1998). Holonic manufacturing scheduling: architecture, cooperation mechanism, and implementation. Computers in Industry, 37, 213-231.

Heragu, S.S., Graves, R.J., Kim, B. \& Onge, A. (2002). Intelligent agent based framework for manufacturing systems control. IEEE Transactions on Systems, Man, and Cybernetics - Part A: Systems and Humans. 32 (5), 560-573.

Iwamura, K., Okubo, N., Tanimizu, Y. \& Sugimura, N. (2006). Real-time scheduling for holonic manufacturing systems based on estimation of future status. International Journal of Production Research, 44 (18-19), 3657-3675.

Janic, M., \& Reggiani, A. (2002). An Application of the Multiple Criteria Decision Making (MCDM) Analysis to the selection of a new hub airport. European Journal of Transport and Infrastructure Research, 2 (2) 113-142.

Kutanoglu, E. \& Sabuncuoglu, I. (1999). An analysis of heuristics in a dynamic job shop with weighted tardiness objectives. International Journal of Production Research, 37 (1), 165-187.

Li, Q., Qu, D. \& Du, L. (2008). Research on hybrid-genetic algorithm for MAS based job-shop dynamic scheduling. Proceedings of the IEEE International Conference on Service Operations and Logistics, and Informatics, IEEE, Beijing, China, 1742-1745.

Leitao, P., \& Restivo, F. (2002). Holonic adaptive production control systems. Proceedings of the $28^{\text {th }}$ IEEE Industrial Electronics Society Annual Conference, IEEE, Sevilla, Spain, 2968-2973.

Leitao, P. (2009). Agent-based distributed manufacturing control: A state-of-the-art survey. Engineering Applications of Artificial Intelligence, 22, 979-991.

Miyashita, K. (1998). CAMPS: A constraint-based architecture for multi-agent planning and scheduling. Journal of Intelligent Manufacturing, 9 (2), 147-154.

Papakostas, N., and Chryssolouris, G. (2009). A scheduling policy for improving tardiness performance. Asian International Journal of Science and Technology in Production and Manufacturing Engineering, 2 (3), 79-89.

Priore, P., Fuente, D., Puente, J. \& Parreno, J. (2006). A comparison of machine-learning algorithms for dynamic scheduling of flexible manufacturing systems. Engineering Applications of Artificial Intelligence, 19 (3), 247-255.

Rabelo, R.J., Camarinha-Matos, L.M. \& Afsarmanesh, H. (1999). Multi-agent based agile scheduling. Robotics and Autonomous Systems, (27), 15-28.

Shen, W. (2002) Distributed manufacturing scheduling using intelligent agents. IEEE Intelligent Systems, 17 (1), 88-94.

Shen, W., Wang, L. \& Hao, Q. (2006a). Agent-based distributed manufacturing process planning and scheduling: A State-of-the-Art Survey. IEEE Transactions on Systems, Man and Cybernetics Part C: Applications and Reviews, 36 (4), 563-577.

Shen, W., Hao, Q., Yoon, H.J. \& Norrie, D.H. (2006b). Applications of agent-based systems in intelligent manufacturing: An updated review. Advanced Engineering Informatics, (20), 415-431.

Shih, H. (2008). Incremental analysis for MCDM with an application to group TOPSIS. European Journal of Operational Research, 186, 720-734.

Smith, R.G. (1980). The Contract Net Protocol: High-Level Communication and Control in a Distributed Problem Solver. IEEE Transactions on Computer, C-29 (12), 1104-1113.

Sousa, P. \& Ramos, C. (1999). A distributed architecture and negotiation protocol for scheduling in manufacturing systems. Computers in Industry, 38, 103-113.

Sudo, Y., Sakao, N. \& Matsuda, M. (2010). An agent behavior technique in an autonomous decentralized manufacturing system. Journal of Advanced Mechanical Design, Systems and Manufacturing, 4 (3), 673-682.

Walker, S.S., Brennan, R.W. \& Norrie, D.H. (2005). Holonic job shop scheduling using a multi agent system. IEEE Intelligent Systems, 20 (1), 50-57. 
Wang, C., Ghenniwa, H. \& Shen, W. (2008). Real time distributed shop floor scheduling using an agent-based service-oriented architecture. International Journal of Production Research, 46 (9), $2433-2452$.

Wang, L., (2001). Integrated design-to-control approach for holonic manufacturing systems. Robotics and Computer Integrated Manufacturing, 17, 159-167.

Wang, T-C. \& Chang T-H. (2007). Application of TOPSIS in evaluating initial training aircraft under a fuzzy environment. Expert Systems with Applications, 33, 870-880.

Wang, Y.C. \& Usher, J.M. (2005). Application of reinforcement learning for agent-based production scheduling. Engineering Applications of Artificial Intelligence, 18, 73-82.

Wong, T.N., Leung, C.W., Mak, K.L. \& Fung, R.Y.K (2006). Dynamic shop floor scheduling in multi-agent manufacturing systems. Expert Systems with Applications, 31, 486-494.

Wooldrigde, M. \& Jennings, N.R. (1995). Intelligent agents: theory and practice. The Knowledge Engineering Review, 10 (2), 115-152.

Yang, C \& Lin, J.S. (1998). The development of a hybrid hierarchical/heterarchical shop floor control system applying bidding method in job dispatching. Robotics and Computer-Integrated Manufacturing, 14, 199-217. 